\title{
Perfil de ácidos graxos de iogurte produzido com diferentes culturas bacterianas*
}

\section{Fatty acid profile of produced with different cultures yogurt startes}

\author{
Marceli Pazini Milani, ${ }^{* *}$ Diego Prado de Vargas, ${ }^{* * *}$ José Laerte Nörnberg ${ }^{\star *}$
}

\begin{abstract}
Resumo
Objetivou-se avaliar o perfil de ácidos graxos do iogurte produzido com diferentes culturas fermentadoras, seu comportamento durante o processo fermentativo e seu valor nutricional (índices aterogênico e trombogênico). Testaram-se três formulações de culturas fermentadoras: Padrão (Lactobacillus bulgaricus e Streptococcus thermophilus); Padrão + probiótico (Lactobacillus acidophilus e Bifidobacterium sp) e probiótico. Amostras do leite obtidas durante e após a fermentação, foram analisadas quanto ao perfil de ácidos graxos. A gordura foi extraída por Bligh e Dyer, a preparação dos ésteres metílicos por Hartman e Lago, a determinação e quantificação por cromatografia gasosa. As diferentes culturas fermentadoras não tiveram efeito sobre o perfil de ácidos graxos do iogurte produzido. O teor de ácido linoleico conjugado não diferiu entre os tratamentos. Observou-se uma variação nos teores de palmítico, palmitoléico e $\alpha$-linolênico durante o processo fermentativo. Entretanto, a utilização de diferentes culturas não teve efeito na relação n6/n3 e nos índices aterogênico (IA) e trombogênico (IT) entre os tratamentos e desses com o leite.
\end{abstract}

Palavras-chave: ácido linoleico conjugado, leite fermentado, funcional.

\begin{abstract}
The objective was to evaluate the fatty acid profile of yogurt produced with different fermenting cultures, their behavior during the fermentation process and its nutritional value (atherogenic and trombogenic indexes). Tree formulations were tested fermenting cultures: Standard (Lactobacillus bulgaricus e Streptococcus thermophilus); Standard + probiotic (Lactobacillus acidophilus and Bifidobacterium sp) and probiotic. Samples of the milk obtained during and after fermentation were analyzed for their fatty acid profile. The fat was extracted by Bligh and Dyer, the preparation of the methyl esters and by Hartman and Lago, determination and quantification by gas chromatography. The different fermenting cultures had no effect on the fatty acid profile of the produced yogurt. The conjugated linoleic acid content did not differ between treatments. There was a variation in the levels palmitic, palmitoleic acid and $\alpha$-linolenic during the fermentation process. However, the use of different cultures had no effect on the relationship n6/n3 and atherogenic index (IA) and thrombogenic (IT) between these treatments and with the milk.
\end{abstract}

Keywords: conjugated linoleic acid, femented milk, functional.

\section{Introdução}

A produção de lácteos fermentados por muito tempo esteve representada pelo iogurte tradicionalmente produzido com cultivos protosimbióticos de Streptococcus salivarius subsp. thermophilus e Lactobacillus delbrueckii spp. Bulgaricus. No entanto, novas culturas vêm sendo estudadas para serem usadas de forma associada ou não à cultura tradicional, quer como agentes biotecnológicos, ou seja, que melhoram as características do produto tradicional, por reduzir a pós-acidificação do iogurte, fato evidenciado pela ação do Lactobacillus acidophilus e Bifidobacterium SP, quer como agentes terapêuticos, que promovem efeitos benéficos nos indivíduos que os ingerem, seja pelo efeito da ingestão dos microrganismos em si como dos metabólidos oriundos do processo fermentativo (Antunes, 2001).

A gordura do leite se caracteriza pela maior proporção de ácidos graxos saturados, com cadeias de 4 a 16 carbonos. Em geral, ácidos graxos saturados tendem a elevar tanto o colesterol LDL como o HDL; Contudo, esse efeito parece estar limitado a ácidos graxos de cadeia entre 10 e 18 carbonos, principalmente o mirístico (C 14:0), palmítico (C 16:0) e possivelmente o láurico (C 12:0). Além disso, a gordura do leite caracteriza-se por ser uma das fontes naturais mais ricas de ácido linoleico conjugado (CLA) (Collomb et al., 2006). A presença de CLA agrega valor ao leite e seus derivados, uma vez que há relatos de seu efeito como anticarcinogênico, redutor da deposição de gordura corporal, inibidor do desenvolvimento de aterosclerose, estimulador da resposta imune (Bhattacharya et al., 2006) e redutor da glicemia, sendo a quantificação destes constituintes nos alimentos uma questão relevante para a saúde dos consumidores. Além do CLA, esse alimento é fonte de ácidos graxos essenciais, linoleico (C18:2 n6) e a-linolênico (C 18:3 n3), o qual está associado ao menor risco de doenças cardíacas isquêmicas, e butirato, que age como potente agente antimutagênico, inibe células cancerígenas e ação antiproliferativa.

A avaliação dos alimentos ou dietas é importante, visto que nem todos os lipídios têm o mesmo potencial no aparecimento de doenças cardiovasculares. Em revisão sobre os efeitos dos

*Recebido em 17 de agosto de 2015 e aceito em 14 de março de 2016.

**Universidade Federal de Santa Maria, Departamento de Ciência e Tecnologia dos Alimentos (DTCA), Santa Maria, RS-Brasil.

**Universidade Federal de Santa Maria, Departamento de Ciência e Tecnologia dos Alimentos (DTCA), Santa Maria, RS-Brasil.

Autor para correspondência: marci_vet@hotmail.com. 
lipídios na ocorrência de doença cardíaca coronariana, Ulbricht; Southgate (1991) verificaram que a avaliação da relação de lipídios polinsaturados/saturados não é adequada para avaliar as dietas ou alimentos, pois apenas três ácidos graxos são de fato hipercolesterolêmicos (C 12:0, C 14:0 e C 16:0). Dessa forma, propuseram a utilização de dois índices na avaliação lipídica dos alimentos, o índice aterogênico (IA) e o índice trombogênico (IT), tais índices constituem uma ferramenta matemática para compreender o valor nutricional dos alimentos estudado.

Pesquisa tem relatado que a adição de bactérias ácido-lácticas (LAB - Lactic Acid Bacteria), especialmente Lactobacillus e as bifidobactérias, em produtos lácteos, pode contribuir para a produção de ácidos graxos livres, pela lipólise da gordura do leite (Coskun e Ondul, 2004).

O objetivo do trabalho foi estudar o perfil de ácidos graxos do iogurte produzido com diferentes culturas fermentadoras, seu comportamento durante o processo fermentativo e o valor nutricional do produto final através dos índices aterogênico e trombogênico.

\section{Material e métodos}

Para obtenção dos iogurtes, foram utilizados $1000 \mathrm{~mL}$ de leite UHT integral, adquirido em estabelecimento comercial e diferentes tipos de cultura láctea. Os ingredientes foram misturados e incubados em banho-maria a $42^{\circ} \mathrm{C}$ para $\mathrm{o}$ processo de fermentação. Subamostras foram coletadas de duas em duas horas, até que a fermentação fosse considerada completa ( $\mathrm{pH} 4,6)$, o que se deu após 6 horas. Medidas de $\mathrm{pH}$ e acidez titulável foram determinadas durante o processo. Após a fermentação, o produto foi submetido a imersão em banho de gelo para reduzir a temperatura imediatamente, sendo então mantido sob refrigeração $\left(5^{\circ} \mathrm{C}\right), 24$ horas após o início do processo fermentativo, um nova sub amostra foi coletada de cada tratamento.

Foram preparados três tipos de iogurte conforme o tipo de cultura utilizada: Padrão (Lactobacillus bulgaricus e Streptococcus thermophilus); Padrão + Probiótico (Lactobacillus acidophilus e Bifidobacterium sp) e Probiótico.

Para determinação dos ácidos graxos a gordura do leite e das amostras de iogurte foram extraídas pelo método Bligh e Dyer (1959), com mistura de solvente água-metanol-clorofórmio a frio. A preparação dos ésteres metílios foi feita por meio do método proposto por Hartman e Lago (1973). O perfil de ácidos graxos foi determinado por cromatografia gasosa, utilizando cromatógrafo Agilent 6890 , equipado com coluna capilar de sílica fundida, SP-2560 (100m X 0,2mm X 0,2mm; Supelco) e detector de ionização em chama (FID). Cada corrida teve duração de 70 minutos. A temperatura do injetor foi de $250^{\circ} \mathrm{C}$ e do detector de $300^{\circ} \mathrm{C}$. A injeção foi no modo "split", com relação $21: 1$. O gás de arraste foi o hidrogênio com fluxo de $40 \mathrm{~mL} / \mathrm{minu}$ to e de pressão na cabela da coluna.

A identificação dos ácidos graxos foi efetuada pela comparação dos tempos de retenção com padrões de ésteres metílicos (FAMEs Mix 37 components, Supelco) e como padrão interno sendo utilizado o ácido heptadecanóico. A quantificação foi determinada pela área do pico do éster metílico dos ácidos graxos, em relação à área total dos picos identificados, expressos em $\mathrm{mg} / \mathrm{g}$ de ácidos graxos totais.
A avaliação da qualidade dietética dos ácidos graxos foi determinada segundo Ulbricht. Southgate (1991), conforme equações abaixo.

Índice Aterogênico $(I A)=\frac{L+4 M+P}{n 6+n 3+0+M^{\prime}}$

Índice Trombogênico $(\mathrm{IT})=\frac{M+P+S}{0,50+0,5 M^{\prime}+0,5 n 6+3 n 3+\left(\frac{n 3}{n 6}\right)}$

Onde,

$\mathrm{L}=$ láurico $(\mathrm{C}$ 12:0)

$M=$ mirístico $(C$ 14:0)

$P=$ palmítico (C 16:0)

n3 e n6 = ácidos graxos polinsaturados das respectivas famílias

$\mathrm{O}=$ oleico

M' = restante dos ácidos graxos monoinsaturados.

Todas as análises foram feitas em duplicata e os resultados submetidos a análise de variância (ANOVA) usando o software Statistica 8 (StatSoft Inc., 2009). As médias foram comparadas usando-se o teste Tukey ao nível de significância de 5\% $(P<0,05)$.

\section{Resultados e discussão}

Os resultados apresentados na Tabela 1 demonstram que a interação entre cultura bacteriana e tempo não foi significativa para as variáveis estudadas. Dessa forma, as diferenças observadas entre o tempo não tem influência da cultura utilizada, e vice-versa. As atividades enzimáticas diferentes de cada cultura iniciadora, têm sido identificadas como fatores que podem influenciar o teor de CLA (ácidos linoleico conjugado) dos produtos lácteos fermentados (Sieber et al., 2004). Lactobacillus acidophilus foi capaz de aumentar o teor de CLA em leites fermentados, devido à presença de alto nível da enzima ácido linoleico isomerase (LIM et al., 2000). No entanto, nesse estudo, as culturas utilizadas não demonstraram tal capacidade.

O perfil de ácidos graxos do iogurte está diretamente relacionado com a matéria-prima utilizada para sua formulação. Entretanto, outra forma de alterar essa característica no produto final, está no processo fermentativo, mais especificamente, nas cepas bacterianas utilizadas para a produção desse alimento. A composição química do alimento lácteo é influenciada diretamente pela atividade metabólica da bactéria, que interage com o meio durante o seu crescimento, convertendo determinados componentes em produtos do seu metabolismo (Heller, 2001).

A cultura fermentadora não teve efeito sobre o perfil de ácidos graxos do iogurte produzido. Entretanto, é possível observar o aumento no teor de butirato no iogurte quando comparado com o leite. Essa diferença não se mostra significativa quando comparamos os tratamentos entre si, mas quando comparamos o teor de butirato do leite com o iogurte produzido, independentemente da cultura utilizada, essa diferença se mostra significativa $(p=0,03)$, entre os valores de 4,43 do leite e $9,52 \mathrm{mg}$ de butirato a cada $100 \mathrm{~g}$ de gordura do iogurte, tendo esse um acréscimo de $115 \%$ no teor de butirato quando comparado com o leite que o originou. A produção de ácido butírico pode conferir propriedades farmacêuticas ao produto, uma vez que estudos já demonstram sua ação na modulação, morte e diferenciação celular, tendo dessa forma uma ação protetora contra o câncer (Nohara et al., 2007). 
Tabela 1: Perfil de ácidos graxos do leite e iogurte produzido com diferentes culturas fermentadoras 24 horas após a fabricação

\begin{tabular}{|c|c|c|c|c|c|c|}
\hline \multicolumn{2}{|c|}{ Ácido graxo } & \multicolumn{5}{|c|}{ Cultura fermentadora* } \\
\hline & & \multirow{2}{*}{$\begin{array}{l}\text { Leite } \\
4,43\end{array}$} & \multirow{2}{*}{$\begin{array}{c}\text { Padrão } \\
7,07\end{array}$} & \multirow{2}{*}{$\frac{\text { Padrão + Probiótico }}{8,58}$} & \multirow{2}{*}{$\begin{array}{c}\text { Probiótico } \\
12,90\end{array}$} & \multirow{2}{*}{$\frac{p}{0,46}$} \\
\hline Butírico & C $4: 0$ & & & & & \\
\hline Caproico & C 6:0 & 0,61 & 0,57 & 0,54 & 0,58 & 0,58 \\
\hline Caprílico & C 8:0 & 0,51 & 0,47 & 0,49 & 0,46 & 0,66 \\
\hline Cáprico & C 10:0 & 1,40 & 1,32 & 1,38 & 1,30 & 0,58 \\
\hline Láurico & C 12:0 & 2,02 & 1,64 & 1,97 & 1,64 & 0,36 \\
\hline Mirístico & C 14:0 & 8,96 & 8,68 & 8,70 & 8,34 & 0,62 \\
\hline Miristoleico & C $14: 1$ & 0,65 & 0,63 & 0,59 & 0,60 & 0,80 \\
\hline Pendadecanoico & C 15:0 & 1,10 & 1,07 & 1,06 & 1,01 & 0,46 \\
\hline Palmítico & C 16:0 & 28,95 & 28,33 & 27,55 & 26,81 & 0,55 \\
\hline Palmitoléico & C $16: 1$ & 1,69 & 1,58 & 1,54 & 1,47 & 0,48 \\
\hline Margárico & C 17:0 & 0,85 & 0,83 & 0,80 & 0,76 & 0,35 \\
\hline Esteárico & C 18:0 & 16,06 & 16,00 & 15,31 & 14,78 & 0,43 \\
\hline Vacênico & C $18-1 t 11$ & 3,80 & 3,70 & 3,53 & 2,96 & 0,18 \\
\hline Oléico & C $18: 1$ n9 & 24,41 & 24,04 & 24,10 & 22,69 & 0,49 \\
\hline Linoléico & C $18: 2$ n6 & 1,67 & 1,63 & 1,71 & 1,57 & 0,50 \\
\hline CLA & C $18: 2 c 9 t 11$ & 0,89 & 0,91 & 0,89 & 0,80 & 0,15 \\
\hline a-Linolênico & C $18: 3$ n3 & 0,34 & 0,29 & 0,33 & 0,31 & 0,63 \\
\hline$\sum$ AGS & & 65,41 & 66,38 & 66,62 & 69,02 & 0,37 \\
\hline$\sum A G I$ & & 34,59 & 33,62 & 33,28 & 30,98 & 0,37 \\
\hline
\end{tabular}

*Padrão: Lactobacillus desbrueckii subsp. Bulgaricus e Streptococcus salivarius subsp. thermophilus. Probiótica: Bifidobacteria.

${ }^{* *}$ Abreviações: CLA: Ácido linoleico conjugado; AGS: Ácidos graxos saturados; AGI: ácidos graxos insaturados.

Resultados expressos em mg/100g de gordura. Significância $(P<0,05)$. bém não diferindo desses para com o leite utilizado para a produção dos mesmos. O valor de IA e IT logo após o término do processo fermentativo não foi diferente, significativamente, para o valor obtido 24 horas após a fermentação.

Segundo Tonial et al. (2010), os IA e IT indicam o potencial de estímuloà agregação plaquetária, ou seja, quanto menores os valores de IA e IT, maior a quantidade de ácidos graxos antiaterogêncios presentes e, consequentemente, maior é o potencial de prevenção de doenças coronarianas. Desta forma, a redução desses índices refletiria em um valor nutritivo mais adequado para a saúde humana. Entretanto, os iogurtes e o leite fermentado não apresentaram melhora com relação ao leite que o originou.

Existe pouca literatura sobre valores de IA e IT. Comparando-se os valores de IA e IT do leite com os obtidos por Ribeiro et al. (2011), os deste trabalho apresentaram-se superiores aos encontrados. A relação n6/ n3 não apresentou diferença significativa entre os tratamentos e desses com o leite. De acordo com a FAO, valores abaixo de 10 sugerem quantidades desejáveis à dieta para a prevenção de riscos cardiovasculares.
O teor de CLA não apresentou aumento significativo do leite para o iogurte produzido, em nenhuma das culturas bacterianas utilizadas. Resultado diferente do relatado por Yadav (2007) em pesquisa com leite de búfala para produção de Dahi probiótico, que observou aumento significativo do teor de CLA durante a fermentação, o qual se manteve constante por até 10 dias de armazenamento.

Como não houve interação entre a cultura fermentadora utilizada e o tempo de fermentação sobre o perfil de ácidos graxos dos iogurtes, faz-se uma análise estatística do efeito do tempo independentemente da cultura utilizada. Dessa forma, é possível observar uma variação significativa durante o processo fermentativo para os ácidos graxos: palmítico, palmitoleico e a-linolênico, em ambos essa variação não é linear, apresentando flutuações no decorre do tempo, aumentando e diminuindo de forma inconstante (Tabela 2).

A Tabela 3 apresenta os índices de IA e IT, os quais não apresentaram diferença significativa entre os tratamentos, tam-
Tabela 2: Perfil de ácidos graxos dos iogurtes em função do tempo após início da fermentação

\begin{tabular}{|c|c|c|c|c|c|c|c|}
\hline \multirow{2}{*}{\multicolumn{2}{|c|}{ Ácido graxo }} & \multicolumn{5}{|c|}{ Tempo (h) } & \multirow{3}{*}{$\begin{array}{l}\mathrm{p} \\
0,08\end{array}$} \\
\hline & & \multirow{2}{*}{$\begin{array}{c}0 \\
4,43\end{array}$} & \multirow{2}{*}{$\begin{array}{c}2 \\
9,8\end{array}$} & \multirow{2}{*}{$\begin{array}{c}4 \\
4,56\end{array}$} & \multirow{2}{*}{$\begin{array}{c}6 \\
18,62\end{array}$} & \multirow{2}{*}{$\begin{array}{c}24 \\
10,17\end{array}$} & \\
\hline Butírico & C $4: 0$ & & & & & & \\
\hline Capróico & C 6:0 & 0,61 & 0,55 & 0,57 & 0,58 & 0,52 & 0,20 \\
\hline Caprílico & C 8:0 & 0,51 & 0,45 & 0,47 & 0,46 & 0,49 & 0,42 \\
\hline Cáprico & C 10:0 & 1,40 & 1,26 & 1,34 & 1,26 & 1,41 & 0,42 \\
\hline Láurico & C 12:0 & 2,02 & 1,82 & 1,50 & 1,80 & 2,01 & 0,43 \\
\hline Mirístico & C $14: 0$ & 8,96 & 8,15 & 8,98 & 7,97 & 8,81 & 0,11 \\
\hline Miristoleico & C $14: 1$ & 0,65 & 0,52 & 0,64 & 0,57 & 0,64 & 0,13 \\
\hline Pendadecanóico & C 15:0 & 1,10 & 1,01 & 1,10 & 0,96 & 1,06 & 0,07 \\
\hline Palmítico & C $16: 0$ & $28,95^{\mathrm{ab}}$ & $27,20^{\mathrm{ab}}$ & $29,28^{a}$ & $24,91^{b}$ & $27,47^{\mathrm{ab}}$ & 0,04 \\
\hline Palmitoleico & C $16: 1$ & $1,69^{a}$ & $1,52^{\mathrm{ab}}$ & $1,57^{\mathrm{ab}}$ & $1,35^{\mathrm{b}}$ & $1,49^{a b}$ & 0,02 \\
\hline Margárico & C 17:0 & 0,85 & 0,78 & 0,85 & 0,72 & 0,78 & 0,09 \\
\hline Esteárico & C 18:0 & 16,06 & 15,2 & 16,6 & 13,94 & 15,01 & 0,17 \\
\hline Vacênico & C $18-1 t 11$ & 3,80 & 3,11 & 3,77 & 2,83 & 3,48 & 0,33 \\
\hline Oleico & C $18: 1 n 9$ & 24,41 & 24,40 & 25,01 & 21,05 & 23,18 & 0,08 \\
\hline Linoleico & C $18: 2 \mathrm{n} 6$ & 1,67 & 1,84 & 1,68 & 1,43 & 1,57 & 0,06 \\
\hline CLA & C $18: 2 c 9 t 11$ & 0,89 & 0,86 & 0,90 & 0,77 & 0,87 & 0,51 \\
\hline a-Linolênico & C $18: 3$ n3 & $0,34^{a}$ & $0,33^{\mathrm{ab}}$ & $0,33^{\mathrm{ab}}$ & $0,23^{b}$ & $0,32^{\mathrm{ab}}$ & 0,001 \\
\hline$\sum A G S$ & & 65,41 & 66,61 & 65,42 & 71,35 & 67,91 & 0,09 \\
\hline$\sum A G I$ & & 34,59 & 33,39 & 34,58 & 28,65 & 32,09 & 0,09 \\
\hline
\end{tabular}

*Abreviações: CLA: Ácido linoleico conjugado; AGS: Ácidos graxos saturados; AGI: ácidos graxos insaturados.

Resultados expressos em mg/100g de gordura. Significância $(P<0,05)$. 
Tabela 3: Qualidade dietética dos iogurtes produzidos com diferentes culturas fermen-tadoras e do leite utilizado como matériaprima

\begin{tabular}{lccccc}
\hline \multicolumn{1}{c}{ Cultura } & IA & IT & n6 & n3 & n6/n3 \\
\hline $\begin{array}{l}\text { Padrão (Lactobacillus bulgaricus e } \\
\text { Streptococcus thermophilus) }\end{array}$ & 2,23 & 3,43 & 1,88 & 0,33 & 5,70 \\
$\begin{array}{l}\text { Padrão + probiótico (Lactobacillus } \\
\text { acidophilus e Bifidobacterium sp) }\end{array}$ & 2,23 & 3,41 & 1,89 & 0,35 & 5,40 \\
$\begin{array}{l}\text { Probiótico } \\
\text { Leite in natura }\end{array}$ & 2,29 & 3,45 & 1,66 & 0,33 & 5.03 \\
\hline
\end{tabular}

*Abreviações: IA: Índice aterogênico; IT: Índice Trombogênico; n6: ácidos graxos ômega 6; n3: ácidos graxos ômega 3.

\section{Referências}

ANTUNES, L.A.F. Microrganismos probióticos e alimentos funcionais. Revista Indústria de Laticínios, v. 6, p. 30-34, 2001.

BHATTACHARIA et al. Biological effects of conjugated linoleic acids in health and disease. Journal of Nutrition Biochemistry, v. 17, p. 789-810, 2006.

COLLOMB, M.et al. Conjugated linoleic acids milk fat: Variation and physiological effects. International Dairy Journal, v. 16, n. 11, p. 1347-1361, 2006.

COSKUN, H.; ONDUL, E. Free fatty acid accumulation by mesophilic lactic acid bactéria in cold stored milk. Journal of Microbiology, v. 42, p. 133-138, 2004.

HELLER, K.J. Probiotic bacteria in fermented foods: product characteristics and starter organisms. American Journal of Clinical Nutrition, v. 73, p. 374-379, 2001

LIM, E.M.; EHRLICH, S.D.; MAQUIN, E. Identification of stressinducible proteins in Lactobacillus delbrueckii spp bulgaricus. Electrophoresis, v. 21, p. 2557-2561, 2000.

NOHARA, K.; YOKOYAMA, Y.; KANO, K. The important role of caspase-10 in sodium butyrate-induced apoptosis, The Kobe Journal of Medical Sciences, Japan, v. 53, n. 5, p. 265-273, 2007.

RIBEIRO, C.G.S; GAMA, M.A.S. et al. Índices de aterogenicidade e trombogenicidade da gordura do leite de vacas consumindo dietas à base de capim-elefante contendo níveis crescentes de óleo de girassol. In: 48 ${ }^{a}$ REUNIÃO ANUAL DA SOCIEDADE BRASILEIRA DE ZOOTECNIA, 48, 2011, Belém, Anais..., Belém, SBZ, 2011.

\section{Conclusões}

As diferentes culturas bacterianas utilizadas para a produção de iogurte não tiveram efeito significativo no perfil de ácidos graxos e nos índices aterogênico e trombogênico. O metabolismo lipídico que ocorre durante o processo fermentativo leva a uma variação inconsistente no perfil de ácidos graxos, que poderá ainda ser explorada com pesquisas que estudem concomitantemente a contagem bacteriana presente nas amostras em diferentes tempos, a fim de avaliar quais os microrganismos predominantes e sua influência na produção e manutenção de compostos benéficos a saúde humana.
SIEBER, R.; COLLOMB, M.; AESCHLIMANN, A.; JELEN, P.; EYER, $H$. Impact of microbial cultures on conjugated linoleic acid in dairy products: a review. International Dairy Journal, v. 14, p. 1-15, 2004.

STATSOFT, Inc. STATISTICA (data analysis software system), v. 8, 2009.

TONIAL, I.B. et al. Caracterização físico-química e perfil lipídico do salmão (Salmo salar L.) Alimentos e Nutrição, v. 21, p. 93-98, 2010.

ULBRICHT, T.L.V.; SOUTHGATE, D.A.T. Coronary heart disease: Seven dietary factors. Lancet, v. 338, p. 985-992, 1991. Disponível em: http://www.sciencedirect.com/science/ article/pii/01406736191846M. Acesso em: 20 Out 2014. doi: 10.1016/0140-6736(91)91846-M.

YADAV, H.; JAIN, S.; SINHA, P.R. Production of free fatty acids and conjugated linoleic in probiotic dahi containing Lactobacillus acidophilus and Lactobacillus casei during fermentation and storage. International Dairy Journal, v. 17, p. 1006-1010, 2007. 